\title{
Revitalization of clinical skills training at the University of the Western Cape
}

\author{
JD Jeggels \\ School of Nursing University of the Western Cape \\ A Traut \\ School of Nursing University of the Western Cape
}

M Kwast

Hoogenschool Arnhem and Nijmegen

\section{Kev words}

Skills lab method, Simulation, Self directed learning, Experiential learning, Revitalization

\section{Correspondence address}

Dr June D Jeggels

School of Nursing

University of the Western Cape

Private Bag X17

Bellville

7560

Tel : (021) 959-2278

Fax:(021) 959-2679

E-mail :jjeggels@uwc.ac.za

\begin{abstract}
Curationis 33 (2): $51-59$
Most educational institutions that offer health related qualifications make use of clinical skills laboratories. These spaces are generally used for the demonstration and assessment of clinical skills. The purpose of this paper is to share our experiences related to the revitalization of skills training by introducing the skills lab method at the School of Nursing (SoN), University of the Western Cape (UWC). To accommodate the contextual changes as a result of the restructuring of the higher education landscape in 2003, the clinical skills training programme at UWC had to be reviewed. With a dramatic increase in the student numbers and a reduction in hospital beds, the skills lab method provided students with an opportunity to develop clinical skills prior to their placement in real service settings.

The design phase centred on adopting a skills training methodology that articulates with the case-based approach used by the SoN. Kolb's, experiential learning cycle provided the theoretical underpinning for the methodology. The planning phase was spent on the development of resources. Eight staff members were trained by our international higher education collaborators who also facilitated the training of clinical supervisors and simulated patients. The physical space had to be redesigned to accommodate audio visual and information technology to support the phases of the skills lab method. The implementation of the skills lab method was phased in from the first-year level. An interactive seminar held after the first year of implementation provided feedback from all the role players and was mostly positive. The results of introducing the skills lab method include: a move by students towards self-directed clinical skills development, clinical supervisors adopting the role of facilitators of learning and experiential clinical learning being based on, amongst others, the students' engagement with simulated patients. Finally, the recommendations relate to tailor-making clinical skills training by using various aspects of teaching and learning principles, i.e. case-based teaching, experiential learning and the skills lab method.
\end{abstract}




\section{Introduction}

The School of Nursing (SoN) at the University of the Western Cape (UWC) is one of only two enrolling institutions for undergraduate nurse training in the Western Cape. Following the political decision to merge institutions of higher learning in 2003 the student intake for the nursing program increased dramatically (Asmal, 2002: 2). This increase in the student numbers presented the school with a challenge to review the undergraduate program in general and the clinical skills training program in particular.

Nurse training in South Africa, traditionally made use of real service settings to develop the students' clinical skills. However, with the current health plan 2010 prioritising primary care as the preferred model of health care delivery, there was a real reduction in hospital beds thus shrinking the access to bedside clinical skills training (Health Western Cape, 2003: 1). With the resultant flooding of the primary care sites, the opportunity for relocating skills training to the comprehensive community health centres was not a viable option. At these centres the professional nurses primarily attend to the patient needs with minimal attention to the clinical learning needs of students. The contextual changes that occurred within the education and health sectors in the country necessitated a review of the methods used to develop the clinical skills of undergraduate nursing students.

Most educational institutions that offer qualifications in health related professions make use of clinical skills laboratories. These clinical laboratories resemble real clinical facilities in which students are able to acquire clinical skills through simulation (Kraakinen \& Arwood, 2009, 1). However, these spaces are generally used for the demonstration and assessment of clinical procedures. It became crucial for the SoN to review the utilization of the existing skills lab. The purpose of this paper is to share our experiences related to the revitalization of skills training by introducing the skills lab method at UWC. The skills lab method per se is an innovation in clinical skills training that has been adapted from the methodology used by our international higher education partners at the Hoogeschool Arnhem and Nijmegen (HAN) and the University of Maastrich.

\section{Design Phase \\ Reviewing the clinical program}

With the restructuring of the higher education institutions in the Western Cape into a common teaching platform, the case-based method of teaching and learning was introduced which challenged us to change our way of teaching clinical skills. Case-based teaching is regarded as a more effective method of instruction than the conventional lecture method in that it stimulates the students' critical thinking skills (Kim, Phillips, Pinsky, Brock, Phillips \& Keary, 2006: 867). Kim, et al $(2006,867)$ suggest that the core attributes of cases are that they are: relevant, realistic, engaging, challenging and instructional and are based in real-world professional contexts. The case scenarios should challenge students to engage in situations that they may encounter in the service settings (Kim, et al 2006 868). According to Thomas, O'Connor, Albert, Boutain and Brandt (2001) the benefits of case-based learning include its contribution to students' ability to organize and recall information, it exposes students to novel experiences, and it stimulates clinical reasoning processes and enhances students' confidence. Traditionally students were given a lecture-demonstration which was followed by practice sessions and then a clinical assessment. Students would often rote learn the steps of the procedure and reproduce these steps during the assessment. It has been the perception at the SoN that traditional skills training did not address the critical thinking skills of students adequately and that we have had to explore alternative strategies by, for example, introducing cases as part of the clinical training programme. Consequently, we adopted a clinical skills training methodology that articulates well with the case-based approach to teaching and learning used by the SoN.

The traditional way of acquiring procedural skills in the clinical service setting was also not a viable option. We had to find a way of exposing large numbers of students to the reality of the service setting within a safe environment. We decided to use simulation which is purported to be a safe vehicle for translating classroom knowledge into clinical skills development. Simulation or modelling imitates the real situation and is generally effected by means of role playing, the use of technical equipment or advanced virtual models (Kraakinen \& Arwood, 2009: 1). Engum, Jefferies and Fischer (2003: 67) suggest that simulation allows students to practice clinical techniques without exposing patients to the negative consequences or the risks associ-

\section{Figure (i): Alignment of Competency: Communication}

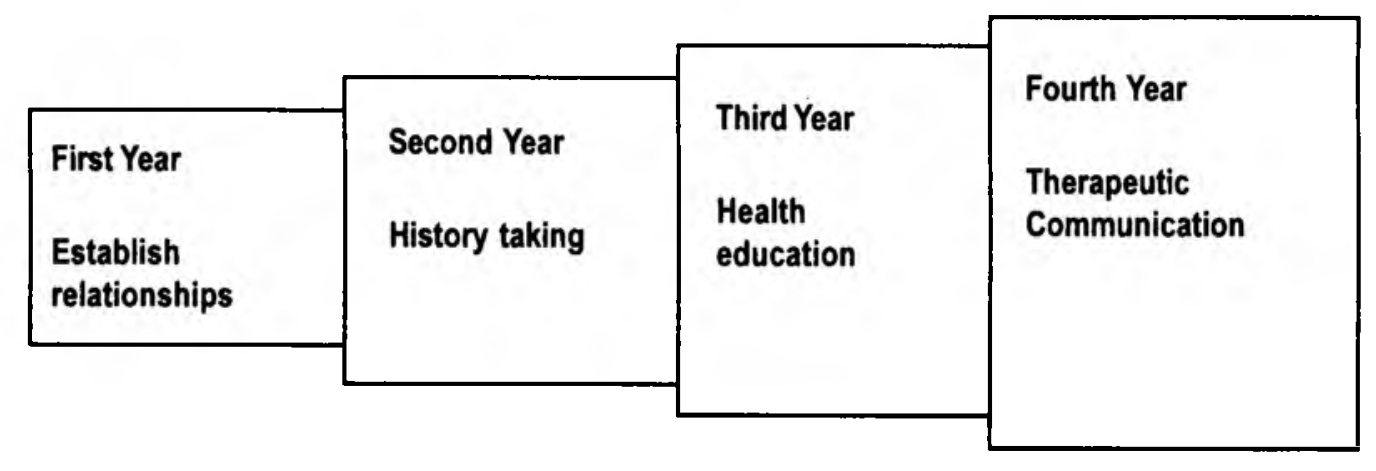


ated with health care training.

We also needed to change the physical laboratory space to accommodate competency-based skills training instead of focusing only on procedurebased activities. Competency refers to the ability to carry out a set of tasks or a role effectively in a simulated setting and to demonstrate an integration of knowledge, skills and attitudes (McConnell, 2001). Benner (2001) as cited in Galloway (2009: 2) describes competency as the midpoint on a continuum between the clinical expertise of a novice and that of an expert. Traditionally undergraduate skills training required of students to master a list of predetermined clinical procedures, e.g., bed baths, administration of medication etc. Once again we realized that procedure based activities did not prepare the students adequately for the reality of the workplace. It did not take into account the learning needs of the individual students and facilitate the attainment of integrated knowledge, skills and attributes. Competency-based skills training focuses on the above mentioned gaps and also ensure the development of lifelong learners (Parker \& Walters, 2008: 70). The skills lab therefore had to resemble the workplace and the teaching and learning activities be based on those performed in the workplace.

The core competencies within the clinical program had to be identified as suggested by Salvatori, Mahoney and Delottinville (2006:380). The SoN identified communication, assessment, care giving and professional development as core competencies which should be reflected in the student workbooks across the year-levels. This would allow students to understand the cumulative nature of skills development. Figure (i) illustrates how communication is introduced across the four year levels. Cases relating to the establishment of relationships involving a diverse client population are included in the interpersonal skills training sessions at the first-year level. At the second year level students are expected to identify high risk medical conditions to ask the appropriate questions during history taking. These high risk conditions e.g. diabetes mellitus (DM) could impact on the health status of a pregnant woman. The midwifery students should there- fore be able to share important information about the effects of DM with clients during their pregnancy. The final year students are expected to communicate and support the patient who develops post-partum depression. Essentially the communication skills mastered at each level form the basis for dealing with the complexity that the various disciplines require of the undergraduate student.

\section{Theoretical underpinning}

A learning theory that fits clinical skills training well is the experiential learning model of Kolb in which he suggests that experience plays a central role in the learning process $(1984,20)$. The learning cycle begins with a concrete experience that the student encounters. The student observes all the aspects of the experience and reflects on it. This is followed by a conscious effort to gain insight and form generalizations (theory) about the experience. The student then tests the theory in new situations. There are four generic adaptive abilities that are necessary for effective learning, i.e.

- $\quad$ Concrete experience (CE) where students immerse themselves in the experience (feeling)

- Reflective observation (RO) in which students must observe and reflect on the experience (watching)

- Abstract conceptualisation (AC) where students create concepts that integrate their observations into theories (thinking)

- $\quad$ Active experimentation (AE) where students apply these theories in new situations (doing) (Kolb, 1984:21).

The skills lab method presented a good fit with the experiential learning model of Kolb. The phases of the skills lab method aligns well with Kolb's experiential approach to adult learning.

The skills lab method was initially designed to develop student competencies prior to the placement of students in real service settings to minimize the danger of harming patients (Galloway, $2009,2)$. However, with the introduction of simulated patients, the method is adapted to reflect real service conditions. This will prepare the undergraduate students in a reality-based environment prior to exposing them to real patients in real service settings. The phases of the skills lab method is illustrated in figure (ii).

The student body is orientated to the skills lab method by explaining the reasons for the introduction of the method and the value that it adds to the development of clinical skills.

Visualization represents the students' first encounter with a skill in the skills lab. The clinical supervisors do a silent demonstration so that the students were able to see the whole picture and are able to gain an insight into specific nursing actions. Students are able to immerse themselves in the experience, observe and reflect on the experience (Kolb, 1984:21).

During the guided practice sessions the clinical supervisors will either demonstrate the skill or allow the students to practice under direct supervision. Additional, relevant information is added at this time to explain underlying principles or specific nursing actions. The students are introduced to the simulated patients who assume the roles of potential clients. Feedback from the clinical supervisors as well as the simulated patient is a key concept during this phase. The students are able to form abstract concepts and generalizations about the experience (Kolb, 1984: 21).

The goal of independent practice is to motivate students to participate in selfdirected clinical skill development activities in order to execute the nursing actions independently. This is done at their own pace and using a method of their choice. Students are encouraged to actively experiment using the case scenarios in their workbooks (Kolb, 1984:21).

The two aspects of the experiential model that are important drivers of the skills lab method are, firstly, exposure to concrete, reality based experiences and secondly, the introduction of adequate, relevant feedback during all the phases of the skills lab method.

Competency-based assessments may be done as formative or summative assessments. Formative assessments are used to guide students towards mastery of competencies and summative assessments used to make judgments about mastery.

\section{Reorganizing clinical learning}

The SoN was compelled to review and reorganize clinical teaching and learning because of large student numbers 
and shrinking access to clinical learning in the service setting. The skills lab method guaranteed such an opportunity for students to practice specific skills repeatedly without causing any harm or discomfort to real patients (Galloway, 2009, 2). Students are able to pace the acquisition of clinical skills with an added benefit of immediate and unbiased feedback from simulated patient-student encounters. The simulated patients would give feedback to the students and facilitate the mastering of amongst others, the students' communication and interpersonal skills (Bokken, Linsssen, Scherpbier, van der Vleuten \& Rethans, 2009: 202).

The same case scenarios that are included in the clinical workbooks are used in the classroom contact sessions. By using the same cases the integration of theory and practice is enhanced. An example would be a scenario where students have to manage conflict related to ignorance about socially acceptable behaviour related to diversity. The student needs to know the theory related to communication and conflict management but more importantly be able to demonstrate a sensitivity to the fact that maintaining eye contact is acceptable by one social grouping but not by another. Traditionally, students experienced the development of clinical skills and nursing theory as two separate entities, which were often managed by different professional groupings, i.e. the clinical sisters within the service units and the lecturers within the university.

\section{Planning Phase}

The skills lab method was introduced in a phased approach. The first two years was spent in developing resources and introducing the method to our service partners, the students and staff of the SoN.

\section{Resource development}

The training of a core group of staff members happened in Holland in 2006.

At HAN and the University of Maastricht, Netherlands, the skills lab method has been used for more than 25 years (Bokken, Van Dalen \& Rethans, 2006:781).

The primary training was followed by a number of workshops locally, facilitated by our international partners. Staff members from all of the nursing disciplines attended the training workshops. Our international colleagues also trained the clinical supervisors as well as the first group of simulated patients. The roles of the various participants in the skills training programme was clarified during this period. The recruitment of interested staff members is important to sustain the roll out of the programme (Salvatori, et al 2006:381).

The role of the clinical program coordinator was pivotal to reorganize the clinical skills training environment, which included the redistribution of human and material resources. The physical space had to be redesigned and specific areas were designated for the video recording and projecting of videotaped images. Computers were installed at the bedside to allow students to view DVDs and have access the intranet. The SIM advanced virtual patients were placed in private rooms to monitor the usage and ensure the maintenance of the highly specialized manikins. According to Nikendei, Zeuch, Dieckmann, Roth, Schafer, Volkl, Schellberg, Hertzog and Junger (2005:122) skills labs may be used for low level skills development (attending to the basic needs of clients) as well as high level skills development (identifying abnormal cardiac and respiratory sounds).

Financial support from various sources facilitated the purchasing as well as installation of audio-visual, video recording and information technology equipment. The initial investment in setting up the recording and projecting equipment necessary for self-directed student activities is costly. The resources that would allow for the introduction of all the phases of the skills lab process was purchased, which underpinned the decision to introduce the method from the first year-level. The technical equipment required for the development of first and second-year level clinical skills were not as costly as, for example, the midwifery birth simulators.

During the planning workshops with our international partners we had to identify the most important role-players for our specific context. Decisions were made regarding the allocation of specific tasks to existing staff members. The clinical skills lab coordinator has to ensure the optimal usage of the skills $\mathrm{lab} / \mathrm{s}$ to allow all the year-levels equal access to the labs. A key task of the skills lab coordinator was the mainte-

\section{Figure (ii): The phases of the skills lab method}

\begin{tabular}{|c|c|c|}
\hline Phases & Key Concepts & Goals \\
\hline Orientation & Rationale for skills lab method & Gaining insight into the method \\
\hline Visualization & Forming an image & Gaining insight into nursing actions \\
\hline Guided practice & $\begin{array}{l}\text { Add critical information / theory } \\
\text { Introduce simulated patient } \\
\text { Give feedback }\end{array}$ & Execute actions under direct supervision \\
\hline Independent practice & Self-directed learning & Execute actions independently \\
\hline Assessment & $\begin{array}{l}\text { Competency based } \\
\text { Feedback }\end{array}$ & $\begin{array}{l}\text { Demonstrate competence } \\
\text { Guidance toward mastery }\end{array}$ \\
\hline
\end{tabular}


nance and control of the equipment. The scheduling of the various activities related to the phases of the skills lab method needed meticulous co-ordination as students from the different year-levels had to be accommodated in the lab. The skills lab co-ordinator from $H A N$ provided valuable information in this regard.

Clinical supervisors had to be trained in the skills lab method as well as trained to use the equipment in the lab. These clinical supervisors are professional nurses with at least two years of discipline specific clinical experience, who participate in most of the phases of the skills lab method. They supervise and accompany the students in the skills lab as well as in the clinical service settings. It is important to draw on their clinical experience, especially during the preparation of learning material and the planning and execution of assessments. Once again this strategy was suggested by our partners from the University of Maastricht.

The simulated patients who are members of the local community were recruited and trained to portrait the role of real patients. Despite the fact that we make use of role playing in clinical skills training, simulated patients are not generally used in nurse training in South Africa. Barrows and Tamlyn $(1980,63)$ have described simulated patients as people who are especially trained to represent a real patient in every detail. Bokken, van Dalen and Rethans (2007:719) suggest that simulated patients must be carefully recruited with attention to their medical history. Bosek, Li and Hicks (2007:3) caution that the use of persons known to students such as fellow students or staff members, can potentially minimize the student's ability to fully appreciate the clinical teaching-learning encounter.

The primary training of the simulated patients was done by our Dutch partners. The simulated patients were orientated to the skills lab method and their value as participants in the skills training program emphasized. As simulated patients they have to provide general as well as specific information to the students. In addition, their role required that they present verbal as well as non-verbal cues during their encounter with students. One of their major responsibilities is to give appropriate feedback to students about spe- cific aspects of the encounter. Giving feedback constitute a major part of the training of the simulated patients (Nestel, Tierney \& Kubacki, 2008: 1122).

\section{Development of learning material}

The next important task was to develop learning material. There was minimal staff relief for this process and much of the material developing was fitted into already full academic timetables. The workbooks were designed to facilitate independent and self-directed learning and students are able to use these books as a guide to all the phases of the skills lab method. In the workbooks students are provided with, amongst others, tools to self-assess prerequisite knowledge, a detailed description of the rationale, planning and execution of a procedure as well as an assessment instrument. The case scenarios used in the classroom contact sessions were included in the workbooks and students were able to engage with different dimensions of the case. Context specific audio visual material is currently being developed to supplement the information in the student workbook.

\section{Introducing the skills lab method to service partners}

A successful, interactive, joint UWCHAN seminar, to which all our service partners were invited, was used to launch the introduction of the skills lab method. The seminar topics ranged from a description of the rationale for introducing an innovative method of clinical skills training in large groups, to reflective inputs from academics, clinical supervisors, simulated patients as well as the under-graduate students. With most of the groundwork in place the new cohort of first-year students started their academic year with an orientation to the skills lab method. The implementation of the method at UWC is presented and reflective comments from the various role players included. The comments were captured during the interactive seminar used to launch the skills lab method at the SoN.

\section{Implementation Phase Orientation}

The new first-year students were orientated to the skills lab method during the general academic orientation program. They viewed a videotape recording that gave an overview of the phases of the skills lab method. Students were issued with course guides and workbooks of the clinical lab module that described these phases in more detail. The concepts related to the skills lab method, e.g. competency and selfdirected learning were clarified during the orientation program.

The students were also introduced to the clinical supervisors and simulated patients and the value of feedback from these participants were discussed. They were informed about the need for self-directed learning and the various ways in which the skills lab method supports independent practice. The need for the production of evidence of participation in independent skills development activities was stressed. Such evidence would provide a paper trail of the mastery of competencies as well as indicate their clinical learning gaps and whether they have made any attempts to attend to these.

\section{Visualization}

Students engage with this phase of the skills lab method during the pre-clinical placement period. The clinical supervisors do a demonstration with groups of $8-12$ students and the students are encouraged to voice their opinion after the visualization of the skill. Other ways of visualizing include the viewing video recordings, CD ROMs and DVDs. Students immerse themselves in the experience and have the opportunity to reflect on the experience (Kolb, 1984:21)

During the seminar the clinical supervisor reflected on the value of visualization, namely, that students are able to see the bigger picture. Prior to their training in the skills lab method, the supervisors were unaware of the degree of distraction that additional theoretical information could present to novices. Supervisors also experienced difficulty in performing a silent demonstration and have had to unlearn internalized behaviour.

\section{Guided practice}

During this phase, which happened during the first term of the first academic year, clinical supervisors engaged a familiar clinical teaching strategy, i.e. the lecture demonstration. 
These sessions were scheduled with small student groups (8-12 students) and a simulated patient in the skills laboratory. At this time, appropriate information was introduced and certain principles underlying the nursing actions explained. The students were encouraged to ask questions for the purpose of clarifying concepts. Students develop generalizations and form abstract concepts about the experience during the guided practice phase of the skills lab method (Kolb, 1984: 21)

The importance of receiving feedback about the various aspects of the competency was discussed after every guided practice session. Feedback from the simulated patient represented the perceptions of potential clients about the level of competency of the student. Students were also introduced to the concept of reflective practice. The clinical supervisors would expose students to reflection by thinking aloud about, e.g. attaining the clinical learning objective/s, mastery of the skills, critical omissions and the need for remediation. Guided practice sessions may be initiated by the supervisor or the student and may involve the broad competency or certain aspects only, e.g. communication or value clarification.

Clinical supervisors did not really experience any challenges with this phase of the skills lab method. They reflected that, they did however, become more aware of the importance of reflective practice when dealing with such a diverse student population. Reflection exposed biases and lead to discussions about the cultural expectations of the patients and their families.

The simulated patients reflected that initially, the students became very defensive after listening to their feedback while the students reported that they felt nervous and threatened by the simulated patients. However, this tension eased after the students realized the value of getting feedback from the simulated patients and they eventually became more familiar with the simulated patient encounters. The clinical supervisors were instrumental in alleviating this tension by reflecting on how the feedback from simulated patients may guide students to modify their behaviour toward patients.

\section{Independent practice}

This phase of the skills lab method has

Figure (iii): Independent practice session

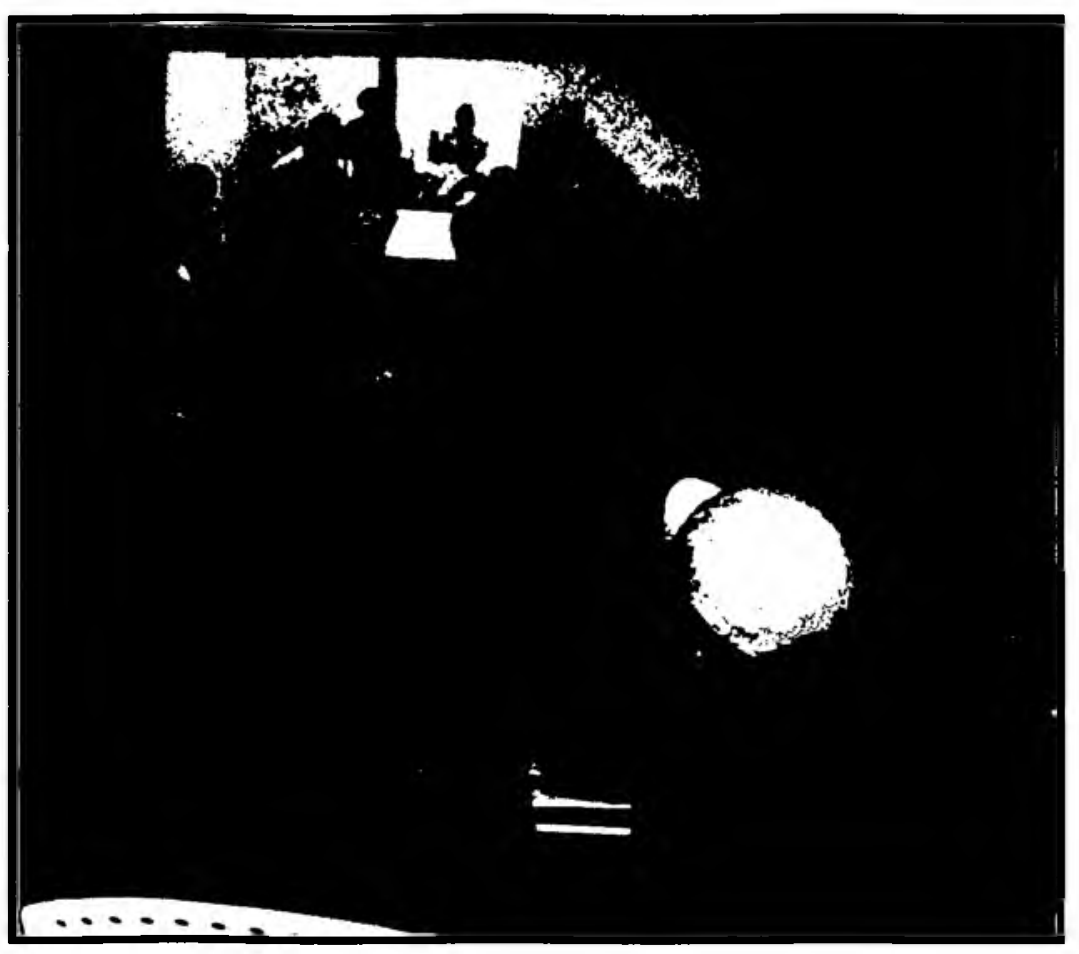

proved to be the most challenging to implement. Students may choose various options to practice independently. They may practice with their peers, schedule a simulated patient encounter or choose to videotape the independent practice session. When they practice on their own or with their peers they are encouraged to self assess the practice session. A peer could score the session and the reflection from the student and feedback from the peer is used to make a judgment about the level of clinical competency displayed by the student. Students consider feedback given by fellow students as a very important aspect of learning (Nikendei, et al 2005:125). During this phase the students use their workbooks extensively and have expressed the value of this resource to provide guidance and present them with alternative dimensions in which to practice the skill. This phase fits well with the active experimentation of effective learners as described by Kolb (1984: 21)

A more objective way to self assess would be to involve a simulated patient in the independent practice session and to videotape the encounter. This has proved to be a novel experience in the clinical skills training process. For the first time students have had to acknowledge their clinical learning gaps when faced with evidence of their performance. They were able to verify the feedback given by the simulated patients as reflected in the projected image. The students could also choose to practice independently with the Sim Man and would then receive electronic feedback. The Sim Man, is a human patient simulator that is able to talk, breath and has a heartbeat, pulse and chest movements. Figure (iii) depicts an example of an independent practice session that was video-taped and is being peer-assessed.

The clinical supervisors reflected that many students do not practice independently and that this phenomenon is impacting the development of their clinical skills. They have questioned the commitment of some of the students to engage in self-directed clinical learning activities and have suggested that students produce evidence of independent practice prior to scheduling appointments for clinical evaluations. Students have admitted to allocating more time to other academic tasks than independent practice activities. However, there are perceptions that prior to structured clinical evaluations, the students generally participate in independent practice sessions. It is suggested that the commitment of students to participate in self-directed clinical skill development be scientifically investigated.

Subsequent strategies to motivate students to engage in independent practice has been; for students to develop learning contracts where they set their 


\begin{tabular}{|l|l|l|}
\hline & Traditional & Innovation \\
\hline Role of student & Students practice procedures repetitively & $\begin{array}{l}\text { Self -directed learners who engage in dif- } \\
\text { ferent aspects of clinical learning }\end{array}$ \\
\hline Role of facilitator & Takes the lead in clinical skills training & $\begin{array}{l}\text { Walks beside the student and gently } \\
\text { guides }\end{array}$ \\
\hline Reality based experiences & Students interact with manikins & $\begin{array}{l}\text { Students interact with } \\
\text { Simulated patients }\end{array}$ \\
\hline Learning & Rote learning & Experiential learning \\
\hline Assessment & $\begin{array}{l}\text { OSCE } \\
\text { Procedure based assessment }\end{array}$ & Competency based assessment \\
\hline
\end{tabular}

own learning goals and for them to develop portfolios of clinical learning evidence to reflect their participation in self-directed activities in the skills lab.

\section{Assessment}

Following the introduction of the skills lab method a tension developed with regard to the teaching and assessment of clinical skills. The traditional ways of clinical evaluation, which included a clinical examination, or Objectively Structured Clinical Evaluation (OSCE) did not align adequately with the skills lab method. Instead of evaluating technical, cognitive and affective skills independently, a need was identified for an integrated type of competency assessment.

During formative assessments by the clinical supervisor, the students' clinical learning gaps were identified. The students were then referred to the skills lab to participate in remedial activities e.g. independent practice sessions. Summative assessments were performed in the skills lab and judgments were made with regard to the level of the student's clinical competency. However during the introduction of the skills lab method the assessment of a competency would involve a simulated patient encounter and include aspects of cognitive, technical and communication skills. Students were being sensitized to different clinical scenarios by including specific examples, as well as the related assessment tools, in their workbooks.

The first attempt at competency assessment required the inclusion of less complex communication and clinical reasoning skills to the assessment of a technical skill (components of the competency: care giving). However, many students focused on the technical skills to the detriment of the other components of the competency.

\section{Evaluation of the skills training method}

The revitalization of the skills lab at UWC presented the SoN with many challenges. However, it has been rewarding to witness that students utilize the skills lab to engage with all the dimensions of experiential learning. Since the skills lab method has been introduced, the changes as illustrated in Figure (iv), have been observed.

\section{Lessons learned}

\section{Enablers}

Many lessons were learned over the two-year period. The enabling issues were varied and numerous and started with the training of eight core members in the skills lab method. The contextual circumstances and clinical learning needs of a diverse student group facilitated the transition to an alternative skills training method. In addition, there was a commitment from most of the staff members to implement the method in all of the nursing disciplines. Collaboration with colleagues from the Universities of Maastricht and HAN in the Netherlands, who have established skills labs and a history of skills trans-. fer to other higher education institutions, facilitated the introduction of the method. They trained the clinical supervisors and simulated patients and the ongoing collaboration has resulted in the acceptance of the method by some of our rural service partners. Through dedicated funding support the SoN was able to equip one skills $\mathrm{lab}$ at UWC, and is systematically equipping two satellite skills labs. The development of learning material is financed on an annual basis, allowing a discipline specific team of academics and supervisors to produce context specific learning material. The learning material is reviewed annually to align it with the students' clinical learning outcomes. Using the same clinical case scenarios in classroom discussions as was used in the skills workbooks facilitated the alignment between theory and practice. These cases were also shared with the academics who present the service courses, e.g. human biology, physics and chemistry.

\section{Challenges}

One of the challenges of implementing the skills lab method at UWC was the maintenance of the skills of the core group of staff members. Most of the group members were program heads and year-level coordinators which meant that subsequent to the primary training many did not participate in the in-house workshops. An omission was that one of the nursing disciplines was not represented in the core group training. Maintaining the interest of all the staff members was challenging because at the time of implementation many other curricular changes was phased in. Colleagues viewed the skills lab method as another add-on that required additional time and energy. However 
despite these barriers there were academics and clinical supervisors who acknowledged the value of the method and maintained the implementation momentum. One of these is the skills lab coordinator who has innovatively, and with the minimum of financial support, produced excellent clinical learning aids to supplement and replace costly disposable items. It is suggested that colleagues who display a keen interest in clinical teaching be included in the primary training of the skills lab method.

Equally important was the control and maintenance of skills lab equipment. The skills lab coordinator is expected to organize the cleaning of equipment, linen and the laboratory. Poor maintenance and control becomes costly and the skills lab environment would then not be conducive to clinical skills training. Satellite labs are generally more challenging to clean and costly to maintain. The maintenance of the skills lab/ $s$ represents much of the hidden costs of subscribing to the method.

Another challenge is to produce resources, e.g. work books, best practice video and DVD material to facilitate the process of self-directed clinical learning. Students should be able to view different dimensions of the competency, e.g. care giving. This means that providing care to a patient may be dependent on contextual factors, namely, the condition of the patient, the service setting and availability of resources. These dimensions should be included as scenarios in the students' workbooks underpinning the need for reviewing and updating resource material. It is expected that this challenge will remain with the SoN until an adequate bank of resources have been developed.

To ensure the acceptance of the skills training method by the student body requires a joint effort from all participants. Academics should use scenarios from the workbooks to integrate theory and practice. Clinical supervisors need to become involved in the development of resource material to ensure ownership of the method. The value of the simulated patients needs to be acknowledged. Students need to sense buy-in from all the role players to positively influence their participation in such a self-directed skills training program. They also need to realize the importance of gathering evidence of clinical learning in a portfolio that carries a credit weighting. The evidence could be used to monitor the transfer of skills from a simulated setting to the real setting. The students' lack of interest to participate in independent practice sessions needs to be scientifically investigated. There is a perception that students do not manage their time effectively between the various academic activities and that close to clinical assessments they tend to spend more time in the skills lab. Only some of them realize that it requires consistent practice to master clinical competencies. The need for an alternative assessment strategy has been identified. Once again the international collaborators have shared their experience with regard to aligning the skills lab method with competency-based assessments.

\section{Conclusion}

The skills lab method of clinical skills development has been successfully introduced at the School of Nursing, UWC. It facilitated the development of excellence in clinical skills development despite the increase in student numbers, limited clinical learning opportunities and inadequate clinical skills development support in the service settings. It is recommended that colleagues facing similar challenges related to clinical skills training strategically tailor-make their programmes to fit their specific contextual situations. The preparation was a lengthy process that required the commitment of at least a small core group of people. A multi dimensional implementation phase is vital to the success of the skills lab method and should therefore be meticulously coordinated. This means that implementation activities should be prioritized, synchronized and phased in over a period of time. It is also important to have access to experts in clinical skills training, but who are sensitive to the contextual needs of the institution to facilitate the introduction of the method. Because of the value that the skills lab method has added to the development of clinical skills training, the methodology will be included in perceptorship training short courses offered by UWC.

\section{References}

ASMAL, K 2002: Press statement by the Minister of Education, Professor Kader Asmal, MP, on the Transformation and Reconstruction of the Higher Education System. 9 December 2002. Pretoria. http://education.pwy.gov,za/ Media/Statements

BARROWS, HS \& TAMLYN, RM 1980: Problem based learning. New York: Springer.

BENNER, P 2001: From Novice to Expert: Excellence and power in clinical nursing practice. New Jersey: Prentice Hall.

BOKKEN, L; VAN DALEN, J \& RETHANS, JJ 2006: The impact of simulation on people who act as simulated patients: a focus group study, Medical Education. 40 (8),781-786.

BOKKEN, L; VAN DALEN, J \& RETHANS, JJ 2007: Response to Blake \& Gusella on the impact of simulation on people who act as simulated patients, Medical Education. 41(7), 719.

BOKKEN, L; LINSSSEN, T; SCHERPBIER, A; VAN DER VLEUTEN, C \& RETHANS, JJ 2009: Feedback by simulated patients in undergraduate medical education: a systematic review of literature. Medical Education 43(3): 202-210.

BOSEK, MS; LI, S \& HICKS, FD 2007: Working with standardized patients: a primer, International Journal of Nursing Education Scholarship. 4, 112.

GALLOWAY, S 2009: Simulation techniques to bridge the gap between novice and competent healthcare professionals. Online Journal of Issues in Nursing, 10913734. 14, 2.

HEALTH WESTERN CAPE, 2003: Healthcare 2010: Health Western Cape's plan for ensuring equal access to quality health care. Department of Health: Western Cape, Cape Town.

KAAKINEN, J \& ARWOOD, E 2009: Systematic review of nursing simulation literature for use of Learning Theory. International Joumal of Nursing Education Scholarship._Online http:www.bepress.com/iines/voll6/ iss 1/artl 6 Accessed on 2 December 
KIM, S; PHILLIPS, WR; PINSKY,L; BROCK, D; PHILLIPS, K \& KEARY, J 2006: A conceptual framework for developing teaching cases: a review and synthesis of literature across literature. Medical Education, 40:867-876.

KOLB, DA 1984: Experiential learning. Englewood Cliffs: Prentice hall

MCCONNELL, E 2001: Competence vs. competency. Nurse Management. 32(5):14.

NESTEL,D; TIERNEY,T\& KUBACKI, A 2008: Creating authentic simulated patient roles: working with volunteers. Medical Education. 42:1111-1146.

NIKENDEI, C; ZEUCH, A; DIECKMANN, P; ROTH, C; SCHAFER, S; VOLKL, M; SCHELLBERG, D; HERTZOG, $W$ \& JUNGER, J 2005: Role-playing for more realistic technical skills training. Medical Teacher. 27(2):122-126.

PARKER, B \& WALTERS, S 2008: Competency based training and $\mathrm{Na}$ tional qualifications framework: Insights from South Africa. Asian Pacific Education Review, 9(1):70-79.

SALVATORI, P; MAHONEY, P \& DEOTTINVILLE, C 2006: An interprofessional communication skills lab: A pilot project. Education for Health. 19(3):380-384.

THOMAS, MD; O'CONNOR, FW; ALBERT, ML; BOUTAIN, D \& BRANDT, PA 2001: Case-based teaching and learning experiences. Issues in MentalHealthNursing 22:517-531 